\title{
KAJIAN LEVEL OF SERVICE (LOS) PADA KAWASAN MIX LANDUSE RUAS JALAN SUDIRMAN - PATI
}

\author{
Supoyo ${ }^{1^{*}}$, lin Irawati $^{2}$ \\ Jurusan Teknik Sipil Fakultas Teknik Universitas Semarang \\ Jalan Arteri Sukarno Hatta - Semarang \\ e-mail : iin.irawati5477@gmail.com
}

\begin{abstract}
Generating and attraction in an area is influenced by the use function of the area. Regions that have an important function of land use, a tendency to have high generation and attraction. The higher the seizure and the pull produced, the more solid the litter is in the area. One area that has a high rise and pull is the mix landuse area. One area that has mix landuse land use conditions is the Sudirman - Pati area. The area consists of commerce, offices and education. The highest side obstacle in the area is parking on the side of the road. The study focused on the study of regional performance using Indonesia Highway Capacity Manual 1997 methods and performance indicators are level of service (LOS). The Sudirman area has a type of road 2/1 UD, with traffic flow of 984.45 PCU/hours, with a large capacity value $(C)=2083.30$ PCU/hours and $D S=0.465$ and at LOS C.
\end{abstract}

Keywords: capacity; degree of saturation; landuse; LOS; traffic flow.

\begin{abstract}
ABSTRAK
Bangkitan dan tarikan di suatu kawasan dipengaruhi oleh fungsi tata guna kawasan tersebut. Kawasan yang memiliki fungsi tata guna lahan penting, kecenderungan memiliki bangkitan dan tarikan yang tinggi. Semakin tinggi bangkitan dan tarikan yang dihasilkan, maka semakin padat laluntas yang berada pada kawasan tersebut. Salah satu kawasan yang memiliki bangkitan dan tarikan yang tinggi adalah kawasan mix landuse. Slah satu kawasan yang memilki kondisi tata guna lahan mix landuse adalah kawasan Sudirman - Pati. Kawasan tersebut terdiri dari perniagaan, perkantoran dan pendidikan. Hambatan samping tertinggi pada kawasan tersebut adalah parkir pada sisi badan jalan. Penelitian difokuskan pada kajian performa kawasan dengan menggunakan metode MKJI 1197 dan indikator performa adalah level of service (LOS). Kawasan Sudirman memiliki tipe jalan 2/1 UD, dengan arus lalulintas sebesar 984.45 SMP/jam, dengan besar nilai kapasitas $(C)=2083.30 \mathrm{SMP} /$ jam dan DS $=0.465$ dan berada pada LOS C.
\end{abstract}

Kata kunci : arus lalulintas; derajat kejenuhan; kapasitas; landuse; LOS.

\section{PENDAHULUAN}

Tata guna lahan (land use) adalah suatu upaya dalam merencanakan penggunaan lahan dalam suatu kawasan yang meliputi pembagian wilayah untuk pengkhususan fungsi-fungsi tertentu (Wendika et.al, 2012). Fungsi tata guna lahan akan mempengaruhi jumlah bangkitan dan tarikan yang memberikan dampak jumlah lalulintas pada suatu kawasan. Pergerakan manusia yang merupakan akibat dari sistem aktifitas yang saling berhubungan dari satu tempat dengan tempat lain, selalu dikaitkan dengan pola hubungan antara distribusi spasial dengan tata guna lahan yang terdapat di suatu wilayah (Akbardin, 2013). Kondisi pergerakan manusia berpengaruh besar terhadap pola aliran lalulintas. Pola aliran lalulintas suatu kawasan akan mempengaruhi performa atau kinerja pada kawasan tersebut.

Mix landuse merupakan tata guna lahan yang didalamnya berdiri berbagai macam fungsi bangunan yaitu fungsi perdagangan barang dan jasa, seperti pasar, pelabuhan, rumah makan, mini market, salon, apotik, industry, dan ruko serta fungsi hunian yaitu permukiman 
(Bulamei et.al, 2015). Salah satu kawasan yang memiliki fungsi sebagai mixed landuse adalah kawasan Sudirman - Pati. Pada kawasan tersebut terdapat fungsi perniagaan, pendidikan dan perkantoran. Kondisi existing menunjukkan bahwa sepanjang kawasan tersebut sering terjadi kemacetan Ialulintas. Menurut Mustikarani dan Suherdiyanto, 2016, masalah kemacetan lalu lintas seringkali terjadi pada kawasan yang memiliki intensitas kegiatan, penggunaan lahan serta jumlah penduduk yang sangat tinggi.

Penyebab terjadinya kemacetan lalulintas di sepanjang kawasan Sudirman - Pati adalah hambatan samping (side friction). Jenis hambatan samping yang menjadi penyebab utama kemacetan lalulintas pada kawasan Sudirman - Pati, adalah adanya parkir pada sisi jalan. Kondisi existing kawasan tersebut ditunjukkan pada gambar 1.

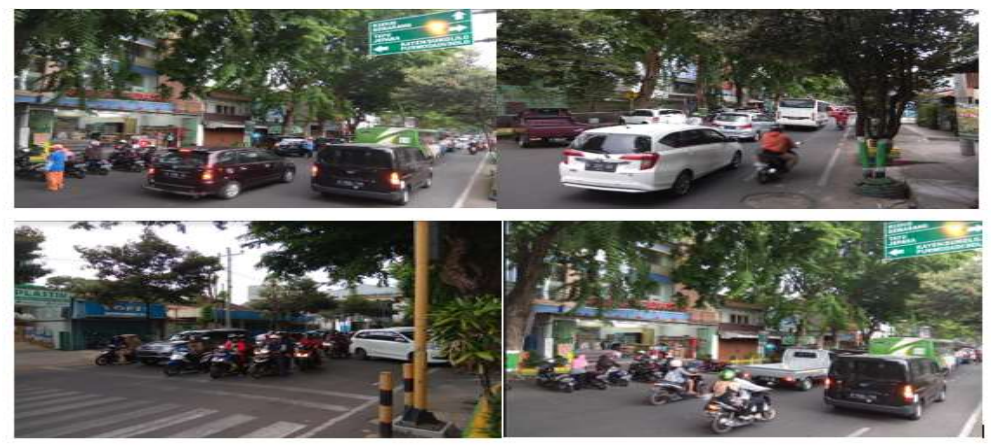

Gambar 1. Kondisi Lalulintas Existing Kawasan Sudirman Pati

Sumber : Dokumentasi Penelitian, 2019

Dari gambar 1 tersebut menunjukkan bahwa keberadaan parkir pada sisi jalan menyebabkan pengurangan lebar jalan. Ruas jalan yang berada di kawasan Sudirman pati memiliki tipe jalan satu jalur satu arah dengan lebar jalur sebesar 7 meter, sedangkan kondisi paling crusial terjadi di depan kawasan niaga Surya. Berdasarkan hal tersebut, maka penelitian ini dilakukan untuk mengkaji keberadaan performa ruas jalan Sudirman yang merupakan kawasan mix landuse dengan indikator Level of Service (LOS) menggunakan metode Manual Kapasitas Jalan Indonesia (MKJI) 1997.

\section{METODOLOGI}

Dalam penelitian ini meliputi 5 tahap yang dilakukan, yaitu tahap 1 ( persiapan ), tahap 2 ( kajian pustaka), tahap 3 (pengumpulan data), tahap 4 (pengolahan dan analisis data ) serta tahap 5 ( pembahasan hasil ). Diagram alir penelitian dipaparkan pada Gambar 2. 


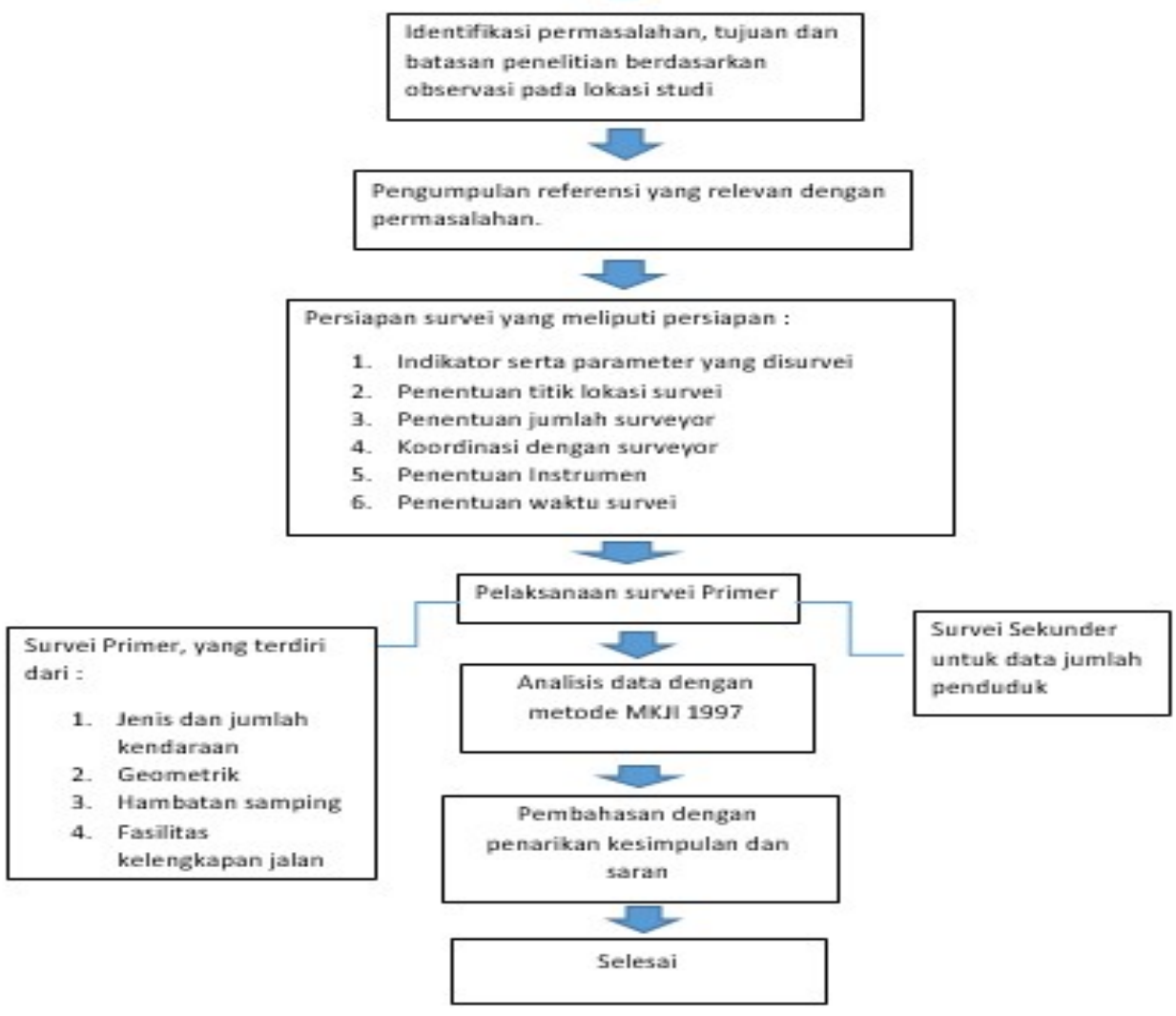

Gambar 2. Diagram Alir Penelitian

Sumber : Peneliti, 2019

Untuk metode analisis data ditunjukkan pada gambar 3. 


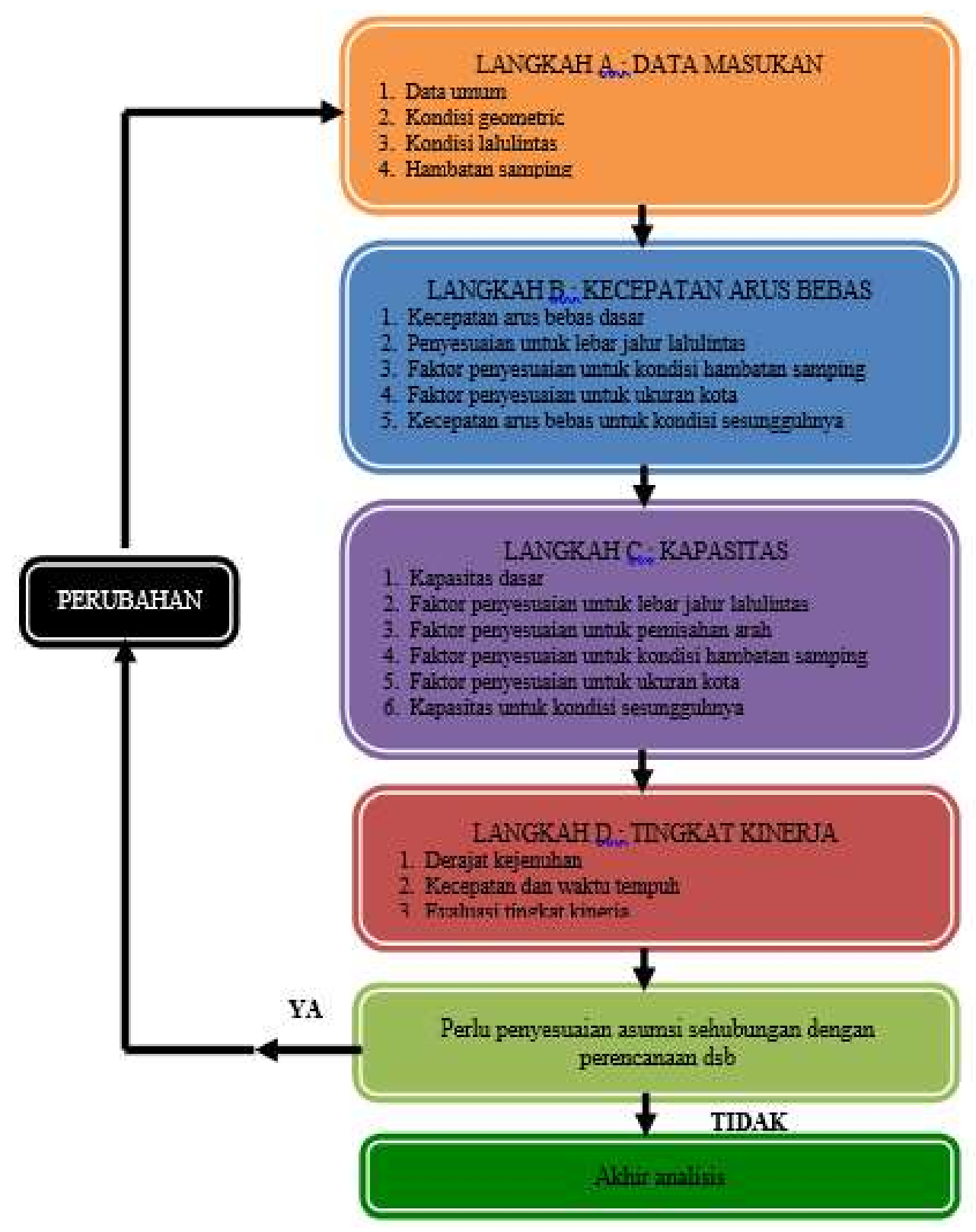

Gambar 3. Metodologi Analisis Data

Sumber : Manual Kapasitas Jalan Indonesia, 1997

\section{HASIL DAN PEMBAHASAN}

Data yang sudah terkumpul selanjutnya dianalisis dengan uraian sebagai berikut :

1. Ekstraksi Data

A. Volume Kendaraan

Volume kendaraan diperoleh dengan pencacahan jumlah kendaraan tiap jam berdasarkan jenis kendaraan. Rekapitulasi jumlah kendaraan berdasarkan hasil survei dapat dilihat pada gambar 4 . 


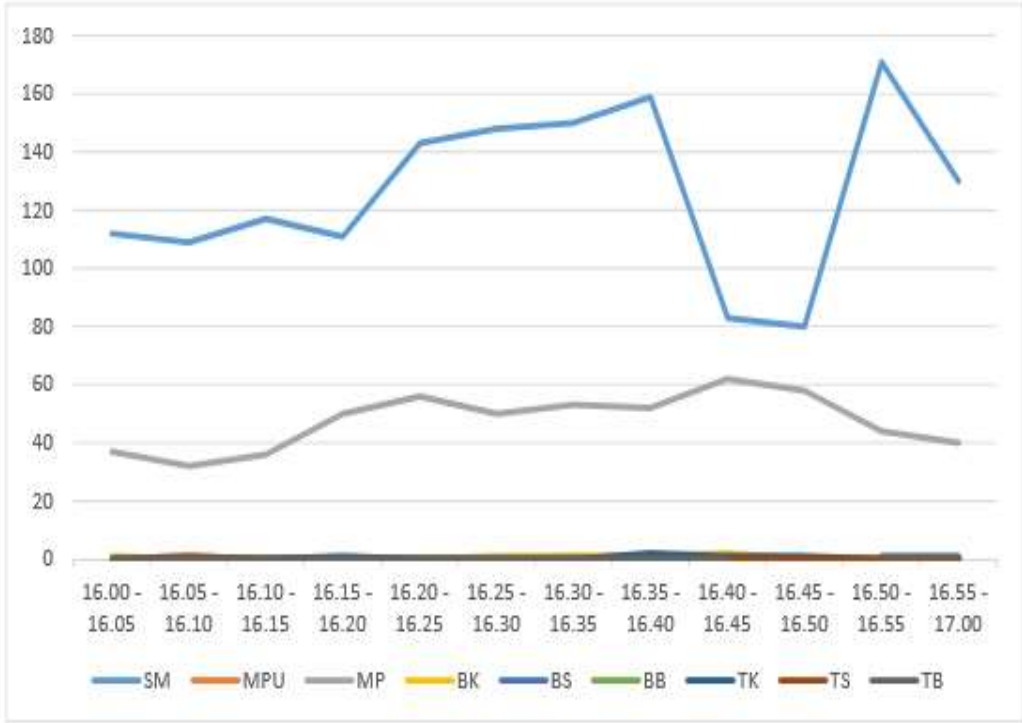

Gambar 4. Grafik Jumlah Kendaraan Dalam Penelitian Dengan Durasi per 5 Menit

Sumber : Peneliti, 2019

B. Geometrik Jalan

Hasil rekapitulasi geometrik jalan dapat dilihat pada gambar 5.

\begin{tabular}{|c|c|c|c|c|c|c|}
\hline Tipe Jalan & $\begin{array}{c}\text { Jumlah } \\
\text { Lajur }\end{array}$ & Jumlah Jalur & $\begin{array}{c}\text { Lebar } \\
\text { Lajur }\end{array}$ & Median & Bahu Jalan & $\begin{array}{c}\text { Lajur } \\
\text { Khusus }\end{array}$ \\
\hline 2/1 UD & 2 & 1 & 3.75 meter & Tidak ada & Tidak ada & 1 meter \\
\hline
\end{tabular}

Gambar 5. Geometrik Jalan Ruas Sudirman

Sumber : Peneliti, 2019

C. Hambatan Samping

Hambatan samping pada segmen jalan yang menjadi wilayah studi penelitian terdiri dari parking on the road, pejalan kaki, kendaraan yang menaikkan dan menurunkan penumpang. Dari hasil pengamatan di lapangan menunjukkan bahwa hambatan yang berupa parking on the road memiliki tingkat hambatan samping yang tinggi. Hal tersebut terlihat dari banyaknya kendaraan yang parkir pada sisi jalan dengan penggunaan lajur jalan sebesar 2.5 meter.

2. Analisis Data

Data yang sudah diekstraksi, selanjutnya dianalisis berdasarkan metode MKJI 1997. Analisis data meliputi arus lalulintas, kapasitas, derajat kejenuhan (DS) dan level of service (LOS). Uraian analisis data setelah ekstraksi data dilakukan adalah sebagai berikut :

a. Arus Lalulintas

Perhitungan untuk arus lalulintas diperoleh dengan mengalikan jumlah kendaraan dengan nilai ekivalen mobil penumpang (EMP). Hasil perhitungan arus lalaulintas ditunjukkan pada gambar 6 . 


\begin{tabular}{|c|c|c|c|c|c|c|}
\hline \multirow{2}{*}{ Waktu } & \multicolumn{5}{|c|}{ Jumlah Kendaraan dan Arus Lalulintas } \\
\cline { 2 - 7 } & \multicolumn{2}{|c|}{ LV } & \multicolumn{2}{c|}{ MC } & \multicolumn{2}{c|}{ HV } \\
\cline { 2 - 7 } & Kend/jam & SMP/jam & Kend/jam & SMP/jam & Kend/jam & SMP/jam \\
\hline $16.00-17.00$ & 584 & 584 & 1513 & 378.25 & 2 & 2.40 \\
\hline $20.00-21.00$ & 706 & 796 & 1593 & 398.25 & 0 & 0 \\
\hline
\end{tabular}

Gambar 6. Analisis Arus Lalulintas

(Sumber : Peneliti, 2019)

b. Kapasitas Jalan

Rumus kapasitas : C = Co $\times$ FCW $x$ FCSP $x$ FCFC $x$ FCCS

1) $\mathrm{Co}=$ kapasitas dasar, yang diperoleh berdasarkan tipe jalan. Tipe jalan pada penelitian ini adalah 2/1 UD, sehingga nilai Co $=1650 \mathrm{SMP} / \mathrm{jam}$ per lajur, sehingga kapasitas dasar $=1650 \times 2=3300$ SMP/jam (MKJI 1997, halaman $5-$ 50, tabel C -1: 1, Jalan Perkotaan).

2) $\mathrm{FC}_{W}=$ faktor penyesuaian kapasitas terhadap lebar lajur. Lebar geometrik pada lajur lalulintas lokasi penelitian adalah 3.75 meter, tetapi karena terdapat pengurangan lebar jalur efektif lalulintas untuk lahan parkir sebesar 2.5 meter, maka nilai $\mathrm{FCW}=0.92$ (MKJI 1997, halaman $5-51$, tabel C $-2: 1$, Jalan Perkotaan).

3) $\mathrm{FC}_{\mathrm{SP}}=$ faktor penyesuaian kapasitas terhadap pemisahan arah. Nilai FCSP $=1$ (MKJI 1997, halaman 5 - 52, tabel C -3 : 1, Jalan Perkotaan).

4) $\mathrm{FC}_{\mathrm{FC}}=$ faktor penyesuaian kapasitas terhadap hambatan samping. Berdasarkan data yang diperoleh di lapangan, kelas hambatan samping yang ada sepanjang jalan adalah sangat tinggi. Hal tersebut terlihat dari penggunaan sisi badan jalan sebagai tempat parkir sepeda motor dan mobil (terjadi pengurangan lebar jalan 2.5 meter pada salah satu sisi jalan), sehingga nilai FCSF $=0.73$ (MKJI 1997, halaman $5-53$, tabel $C-4: 1$, Jalan Perkotaan yang tidak memiliki bahu jalan)

5) $\mathrm{FCCS}=$ faktor penyesuaian kapasitas terhadap ukuran kota. Ukuran kota didasarkan pada jumlah penduduk kota Pati, sehingga nilai FCCS $=0.94$ (MKJI 1997, halaman 5 - 54, tabel C -5 : 1, Jalan Perkotaan)

Dari uraian tersebut di atas, maka nilai kapasitas (C), dapat dihitung sebagai berikut :

$C=3300 \times 0.92 \times 1 \times 0.73 \times 0.94=2083.30 \mathrm{SMP} / \mathrm{jam}$.

c. Derajat Kejenuhan

Setelah diperoleh nilai arus (V) dan kapasitas (C), maka dilakukan analisis perbandingan arus dan kapasitas (V/C) yang merupakan nilai derajat kejenuhan. Nilai V/C tersebut akan digunakan sebagai penentu level of service (LOS) dalam menilai performa (kinerja) ruas jalan. Dari perhitungan diperoleh nilai $D S=0.46$ dan 0.48 yang terletak pada range $0.44-0.74$, sehingga dapat ditentukan level of service (LOS) yang berada pada LOS C. Kinerja ruas jalan pada LOS C menunjukkan bahwa kebebasan bermanuver di dalam aliran lalulintas semakin terbatas dan perpindahan lajur membutuhkan kewaspadaan pengemudi. Kondisi tersebut menunjukkan bahwa jalan berada pada kondisi yang kurang ideal. Batasan kinerja ideal suatu jalan adalah apabila jalan tersebut berada pada LOS B.

\section{KESIMPULAN}


Berdasarkan hasil analisis yang dilakukan, maka dapat diambil kesimpulan bahwa nilai $\mathrm{V}$ rata - rata pada kawasan Sudirman adalah 984.45 SMP/jam, dengan besar nilai kapasitas $(C)=2083.30 \mathrm{SMP} / \mathrm{jam}$ dan DS $=0.465$, sehingga kinerja ruas jalan di kawasan Sudirman berada pada level of service $($ LOS $)=C$.

\section{DAFTAR PUSTAKA}

Akbardin, J., 2013, Kajian Model Bangkitan Pergerakan Kawasan Pendidikan Jalan Sultan Fatah Kota Demak, Portal Jurnal Universitas Pendidikan Indonesia, Volume 11 no 1, Januari 2013

Bulamei, E.P.A., Tharoreh, C.R., Moniaga, L.I., 2015, Perubahan Penggunaan Lahan di Sekitar Kawasan Pelabuhan Bitung, Jurnal Arsitektur, 2015

Departemen Pekerjaan Umum. (1997). Manual Kapasitas Jalan Indonesia (MKJI). Direktorat Jenderal BinaMarga, Jakarta

Ilham, A., Anggreaini, R., Isya, M., 2013, Evaluasi Kinerja Jalan (Studi Kasus Jalan Teuku Muhammad Hasan Aceh), Jurnal Teknik Sipil ISSN 2302-0253, Pascasarjana Universitas Syiah Kuala

Marunsenge, S.G., Timboeleng, A.J dan Elisabeth, L., 2015, Pengaruh Hambatan Samping Terhadap Kinerja Pada Ruas Jalan Panjaitan (Klenteng Ban Hing Kiong) Dengan Menggunakan Metode MKJI 1997, Jurnal Sipil Statik Vol.3 No.8 Agustus 2015 (571582) ISSN: 2337-6732 571

Mustikarani, W dan Suherdiyanto., 2016, Analisis Faktor - Faktor Penyebab Kemacetan Lalulintas di Sepanjang Jalan H Rais A Rahman (Sui Jawi) Kota Pontianak, Jurnal Edukasi, Vol.14, No.1, Juni 2016

Wendika, Y. D., Soeryamassoeka, B.S dan Yuniarti, E., 2012, Pengaruh Perubahan Tata Guna Lahan Terhadap besarnya Debit (Q) Pada Suatu Kawasan (Study Kasus Pasar Flamboyan) Pontianak, Jurnal Teknis Sipil Untan Vol. 12 No. 2. 